\title{
Urokinase Gene 3'-UTR T/C Polymorphism Is Associated With Oral Cancer
}

\author{
Ming-Hsui Tsai, ${ }^{1}$ Wen-Chi Chen, ${ }^{2,3}$ Huey-Yi Chen, ${ }^{2,4}$ and Fuu-Jen Tsai ${ }^{2,5 *}$ \\ ${ }^{1}$ Department of Otolaryngology, China Medical University Hospital, Taichung, Taiwan \\ ${ }^{2}$ Department of Medical Genetics, China Medical University Hospital, Taichung, Taiwan \\ ${ }^{3}$ Department of Urology, China Medical University Hospital, Taichung, Taiwan \\ ${ }^{4}$ Department of Obstetrics and Gynecology, China Medical University Hospital, Taichung, Taiwan \\ ${ }^{5}$ Department of Pediatrics, China Medical University Hospital, Taichung, Taiwan
}

\begin{abstract}
Urokinase is thought to be involved in the formation of oral cancer, although there is a lack of genetic evidence. Our aim was to study single nucleotide polymorphisms in order to investigate the possibility. A total of 130 oral cancer patients and 105 controls were studied. Polymerase chain reaction (PCR) based restriction analysis was used to identify the $\mathrm{C} / \mathrm{T}$ polymorphism of the urokinase gene, which is located on the $3^{\prime}$ untranslated region ( $3^{\prime}$-UTR) of chromosome 10 . There was a significant difference in the distribution of the urokinase gene $3^{\prime}$ UTR C/T polymorphism frequency between cancer patients and the normal control group $(P<0.05)$. The "T" allele was promi-

the risk of the "T" allele in cancer patients was $2.71(95 \% \mathrm{Cl}=1.325 \sim 5.562)$. The cancer patients were further categorized according to gender and whether or not they were habitual smokers or betel nut chewers. These clinical parameters were then compared with tumor cell differentiation and tumor progression. No significant differences were found. Therefore, the urokinase gene $3^{\prime}$-UTR "T" allele is associated with oral cancer and may play a role in oral cancer formation. However, we did not find the relationship between tumor progression and this polymorphism. J. Clin. Lab. Anal. 18:276-279, $2004 . \quad$ (c) 2004 Wiley-Liss, Inc.
\end{abstract} nent in the cancer group. The odds ratio for

Key words: urokinase; oral cancer; single nucleotide polymorphism

\section{INTRODUCTION}

Urokinase, a plasminogen activator that cleaves plasminogen to plasmin and hence stimulates fibrinolysis, is proposed to be an important factor in the progression of oral cancer (1). Urokinase activity of malignant oral mucosa was first detected by Ljungner et al. (2). Nozaki et al. (3) examined oral cancer tissue by immunohistochemical staining and found that the expression of urokinase is correlated with tumor invasion and regional lymph node metastasis. Furthermore, Clayman et al. (1) found overexpression of the urokinase gene in oral cancer patients and suggested that urokinase could promote tumor invasion. Therefore, urokinase may play a role in tumor progression. However, there is a lack of genetic evidence to support the hypothesis that urokinase is associated with oral cancer formation or progression.

Oral cancer is a malignancy commonly seen in Taiwanese who habitually chew betel quid and/or smoke (4). Betel quid chewing causes oral mucosal inflammatory responses, oral submucosal fibrosis, DNA damage, and dysplasia (5). The most common chemical constituent of betel nut is arecholine, an alkaloid that has been shown to cause cytotoxicity effects on cultured human gingival fibroblasts (6). Therefore, the interaction between environmental and genetic factors is thought to be involved in the onset of the disease (7).

The urokinase gene is located at chromosome 10q24 (8). A C/T polymorphism at +4065 nucleotide was previously reported (STS Accession number: G27040) by Tripputi et al. (8). The polymorphic site is located at $3^{\prime}$-UTR (untranslated region) of the urokinase gene. Two other polymorphisms have been reported: a $\mathrm{C} / \mathrm{T}$

*Correspondence to: Fuu-Jen Tsai, MD, PhD, Department of Medical Genetics and Pediatrics, China Medical University Hospital, No. 2 Yu-Der Road, Taichung 404, Taiwan.

E-mail: d0704@www.cmuh.org.tw

Received 25 July 2003; Accepted 28 May 2004

DOI $10.1002 /$ jcla.20037

Published online in Wiley InterScience (www.interscience.wiley.com). 
substitution in exon 6 and a T/C change in intron 7 (9). The polymorphic site located at 3'-UTR (untranslated region) of the urokinase gene was chosen for this study because it was previously studied for other cancers in our laboratory. Our aim was to investigate whether this polymorphism is associated with oral cancer by using polymerase chain reaction (PCR) based restriction analysis.

\section{PATIENTS AND METHODS}

\section{Patient Selection}

A total of 130 patients (10 women, 120 men) who were diagnosed in this hospital as having oral cancer were investigated (average age 53.27 \pm 12.27 years, range 22-79 years). The diagnosis was made from pathological specimens taken from the mouth either from total excision or biopsy. All tumors were squamous cell carcinoma. There were 41 well differentiated, 68 moderately differentiated, and 21 poorly differentiated cell types according to pathological grading. A total of 96 patients $(73.8 \%)$ habitually chewed betel quid for more than 10 years. A total of 116 patients $(89.2 \%)$ habitually smoked for more than 10 years. There were 95 patients $(73.1 \%)$ who both smoked cigarettes and chewed betel quid. Only 11 patients $(8.5 \%)$ neither smoked cigarettes nor chewed betel quid. Patients were followed for at least 3 years. Recurrence was defined as either locally or systemic recurrent tumor found during the follow-up period. There were 41 patients with recurrent tumors found in this study. There were 106 unrelated healthy individuals from the same area who were used as controls. There were 61 males and 45 females in the control group (age range from 40 years to 87 years with an average of $53.02 \pm 10.08$ years). Informed consent was obtained from each individual enrolled in this study.

\section{PCR}

PCR was carried out to a total volume of $50 \mu 1$, containing genomic DNA, 2-6 pmole of each primer, $1 \mathrm{X}$ Taq polymerase buffer $(1.5 \mathrm{mM} \mathrm{MgCl})$, and 0.25 units of AmpliTaq DNA polymerase (Perkin Elmer, Foster City, CA). The primer for the urokinase gene 4065 polymorphism $\mathrm{C} / \mathrm{T}$ was designed as 5'-CCGCAGTCACACCA AGGAAGAG- $3^{\prime}$ and 5'-GCCTGAGGGTAAAGC TATTGTCGTGCAC- ${ }^{\prime}$, according to the published data from Medline (STS Accession: G27040). PCR amplification was performed in a programmable thermal cycler GeneAmp PCR System 2400 (Perkin Elmer). The cycling conditions for the urokinase gene $3^{\prime}-$ UTR C/T polymorphism were set as follows: one cycle at $94^{\circ} \mathrm{C}$ for $5 \mathrm{~min}, 35$ cycles at $94^{\circ} \mathrm{C}$ for $30 \mathrm{sec}, 58^{\circ} \mathrm{C}$ for
$30 \mathrm{sec}$, and $72^{\circ} \mathrm{C}$ for $40 \mathrm{sec}$, and one final cycle of extension at $72^{\circ} \mathrm{C}$ for $7 \mathrm{~min}$.

The PCR product of $210 \mathrm{bp}$ was mixed with two units ApaL I (New England Biolabs, Beverly, MA) and the reaction buffer according to the manufacturer's instructions. The restriction site was designed to be located at the allele of $3^{\prime}$-UTR (T) to form a digestible site. Two fragments of $185 \mathrm{bp}$ and $25 \mathrm{bp}$ were present if the product was digestible. The reaction was incubated for 3 $\mathrm{hr}$ at $37^{\circ} \mathrm{C}$. Then, $10 \mu \mathrm{l}$ of the product was loaded into $3 \%$ agarose gel containing ethidium bromide for electrophoresis. The polymorphism was divided into three groups: digestible (TT homozygote), indigestible (CC homozygote), and $\mathrm{C} / \mathrm{T}$ heterozygote. Because the 25-bp segment would have easily been missed, we sequenced it to confirm its presence. Before sequencing, PCR fragments were purified from the agarose gel using a QIAEX II Kit (Qiagen, Dusseldorf, Germany). Direct sequencing was performed using a dRhodamine DyeDeoxy Terminator Sequencing Kit (PE Applied Biosystems, Foster City, CA) with an ABI Prism 377 DNA Sequencer (PE Applied Biosystems).

We analyzed and compared the difference in allelic frequency distribution of this polymorphism between the control and stone patient groups by the chi-square test. The software used for the calculation was the SPSS $^{\circledR}$ system (Chicago, IL). Results were considered statistically significant when the probability of findings occurring by chance was less than $5 \%(P<0.05)$.

\section{RESULTS}

Figure 1 shows the result of PCR-based restriction analysis. There was no TT homozygote in either group according to the sequencing analysis (Fig. 2). The

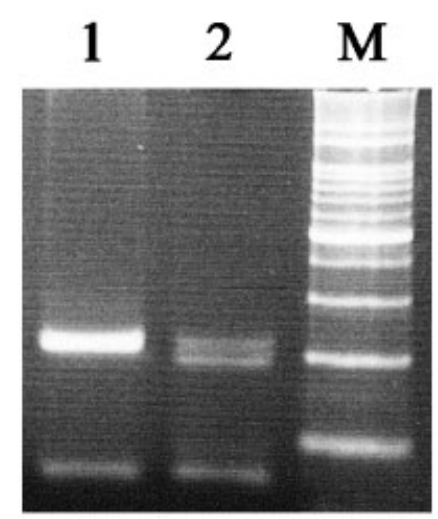

Fig. 1. PCR-base restriction analysis of the urokinase gene $3^{\prime}$-UTR Apal I polymorphism shown on $3 \%$ agarose electrophoresis. The polymorphic region was amplified by PCR resulting in an undigestable fragment in lane $1(210 \mathrm{bp})$ and a heterozygote in lane 2 (185 bp and 25 bp). M: marker (lane 3), 100-bp ladder. 


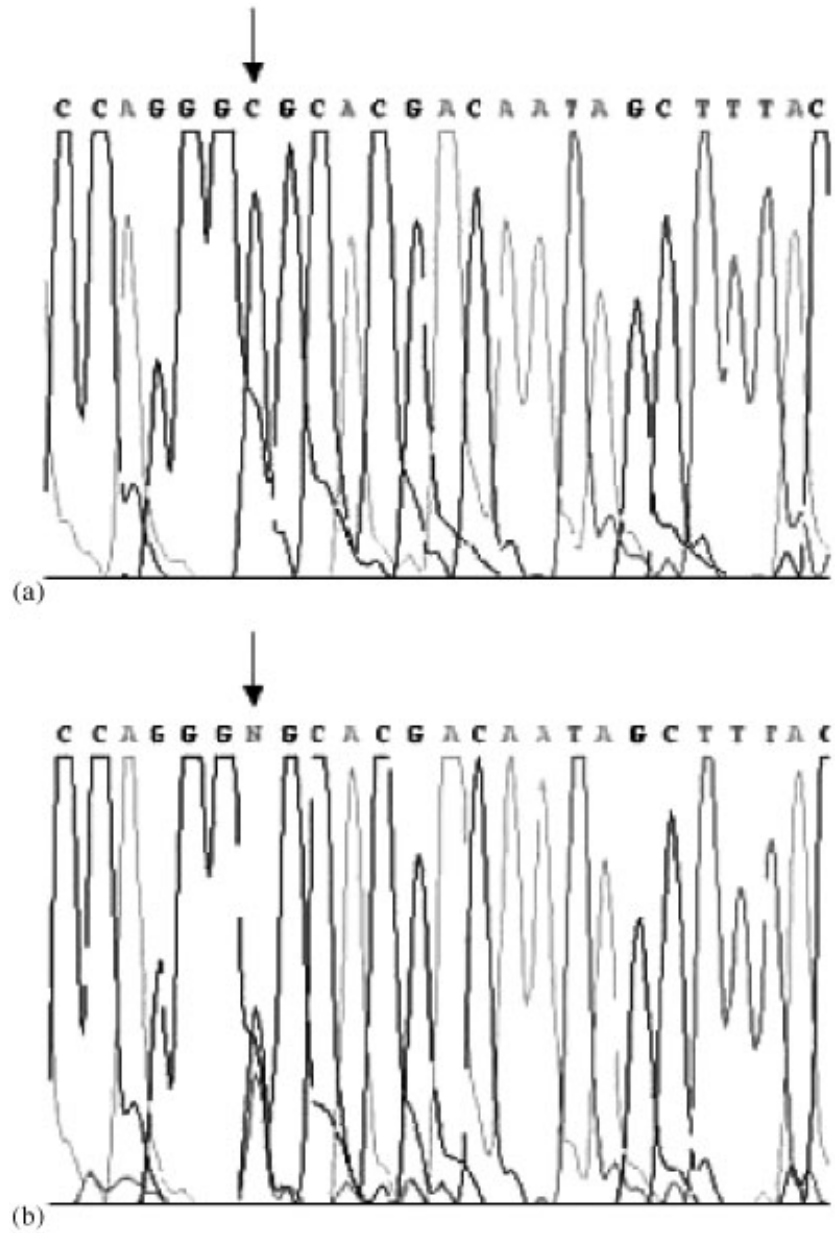

Fig. 2. Sequencing of the polymerase chain reaction products of the urokinase gene $3^{\prime}$-UTR T/C polymorphism showed a: "CC" homozygote (arrowhead) and b: "CT" heterozygote.

frequencies of the genotypes in the cancer and control groups are shown in Table 1. There was a significant statistical difference between the cancer patient and normal control groups (chi-square test, $P=0.041$ ). The $\mathrm{C} / \mathrm{T}$ heterozygote was more prominent in the cancer group $(12.3 \%)$ than in the control group $(4.7 \%)$. Odds ratio for the $\mathrm{C} / \mathrm{T}$ heterozygote in the formation of oral cancer was $2.83(95 \% \quad \mathrm{CI}=1.349 \sim 5.960)$. Further categorization of the patients and controls based on smoking and betel quid chewing as well as gender did not reveal significant differences in the distribution of the genotype.

The data were further subdivided into $\mathrm{C}$ and $\mathrm{T}$ groups according to the allelic frequencies in each group (Table $1, P=0.046$ ). The allelic distribution of the $\mathrm{C} / \mathrm{T}$ polymorphisms of the $3^{\prime}$-UTR of the urokinase gene in normal healthy subjects was: $\mathrm{C}$ allele, 0.976 and $\mathrm{T}$ allele, 0.024. Cancer patients showed a distribution of $\mathrm{C}$ allele, 0.938 and $\mathrm{T}$ allele, 0.062 . The odds ratio $(\mathrm{OR})$ for the
TABLE 1. Frequency of genotype and allelic distribution of the urokinase gene $3^{\prime}$-UTR T/C polymorphism in patients with oral cancer and normal individuals (chi-square test)

\begin{tabular}{lcccc}
\hline Genotype & CC & $\mathrm{C} / \mathrm{T}$ & Total & $P$-value \\
\hline Control & $101(95.3 \%)$ & $5(4.7 \%)$ & 106 & $0.041^{\mathrm{a}}$ \\
Cancer & $114(87.7 \%)$ & $16(12.3 \%)$ & 130 & \\
Odds ratio & & 2.83 & & \\
\multicolumn{5}{c}{$(95 \% \mathrm{CI}=1.349 \sim 5.960)$} \\
Allelic & $\mathrm{C}$ & $\mathrm{T}$ & Total & $P$-value \\
frequency & & & & \\
\hline \multicolumn{5}{c}{} \\
Control & $207(97.6 \%)$ & $5(2.4 \%)$ & 212 & $0.046^{\mathrm{a}}$ \\
Cancer & $244(93.8 \%)$ & $16(6.2 \%)$ & 260 & \\
Odds ratio & & 2.71 & & \\
& & $(95 \% \mathrm{CI}=1.325 \sim 5.562)$ & & \\
\hline
\end{tabular}

${ }^{\mathrm{a}} P<0.05$

TABLE 2. Frequency of genotype distribution of the urokinase gene $3^{\prime}$-UTR $T / C$ polymorphism in patients with oral cancer according to ender, and whether or not they were habitual smoker or betel nut chewers (chi-square test)

\begin{tabular}{lcrcr}
\hline Genotype & $\mathrm{CC}$ & $\mathrm{C} / \mathrm{T}$ & Total & $P$-value \\
\hline Differentiation & & & & 0.479 \\
$\quad$ Well & $36(87.8 \%)$ & $5(12.2 \%)$ & 41 & \\
$\quad$ Moderately & $58(85.3 \%)$ & $10(14.7 \%)$ & 68 & \\
Poorly & $20(95.2 \%)$ & $1(4.8 \%)$ & 21 & \\
Recurrence & & & & 0.978 \\
$\quad$ No & $78(87.6 \%)$ & $11(12.4 \%)$ & 89 & \\
Yes & $36(87.8 \%)$ & $5(12.2 \%)$ & 41 & \\
\hline
\end{tabular}

risk of the $\mathrm{T}$ allele in cancer patients was 2.71 with a $95 \%$ confidence interval $(95 \% \mathrm{CI})$ ranging from 1.325 to 5.562 .

No statistical differences among cancer cell differentiation were found according to the distribution of the $3^{\prime}$-UTR C/T polymorphism in cancer patients categorized into subgroups (Table $2, P=0.479$ ). The data also indicated no significant difference between recurrence and nonrecurrence. Furthermore, according to the data, the variations of the $\mathrm{C} / \mathrm{T}$ polymorphism did not differ between the clinical parameters of as smoking, betel quid chewing, and gender in cell differentiation.

\section{DISCUSSION}

The findings indicate that the urokinase gene $3^{\prime}$-UTR " $T$ " allele is associated with oral cancer. Individuals possessing the "T" allele in the 3 '-UTR of the urokinase gene have a higher incidence of developing oral cancer (2.71-fold) than those who do not. The evidence 
indicates that the urokinase gene $3^{\prime}$-UTR " $T$ " allele is a candidate genetic marker for oral cancer.

Complex diseases such as diabetes, cancer, asthma, and arthritis are probably due to subtle changes in multiple genes caused by environmental and life-style factors. Dissecting the genetics of common and complex disorders such as cancer remains one of the great challenges in human genetics. Oral cancer is considered to be a composite of multigenic diseases involving several overlapping autoimmune responses, each one mediated by a distinct genetic profile. Therefore, studying the genetic polymorphisms of different genes will further clarify the relationship between genetics and cancer formation. The association between oral cancer and various genetic markers has helped increase our knowledge of the genetics of cell response and pathogenesis of oral cancer.

Yasuda et al. (10) reported that urokinase plays a significant pathophysiologic role in head and neck tumor progression. However, Barlow and Southam (11) only identified the activity of urokinase in blood vessels of frozen sections of oral cancer, whereas the malignant epithelial cells did not show the activity. In our study, we did not find a difference between tumor differentiation and the urokinase gene $3^{\prime}$-UTR C/T polymorphism. There was also no difference between tumor progression and this polymorphism. The difference was evident only by comparing the cancer patients with the control group. Therefore, the actual role urokinase plays in the progression of oral cancer remains to be clarified.

Over $70 \%$ of oral cancer patients in this study smoked cigarettes and chewed betel quid, which indicates a strong association between the two habits and oral cancer. Smoking is a common worldwide risk factor for oral cancer (12). However, betel quid chewing is common only in Asian countries, including Taiwan. A high coincidence of cancer patients who smoke cigarettes and chew betel quid suggests that their interaction has carcinogenic effects. Further study of the interaction between smoking and betel quid chewing may help in understanding the role risk factors play in oral cancer.

In an epidemiological study, betel chemical constituents were found to be possible causes of oral cancer (4). However, the exact mechanism is unclear. Sudqvist et al. (13) found that betel nut alkaloids have cytotoxic and genotoxic effects in cultured human buccal epithelial cells. Chang et al. (14) found a synergistic effect of nicotine on arecholine-induced cytoxicity in human bucosal fibroblasts. It is known that urokinase is involved in the degradation of plasminogen and fibrinolysis. Therefore, urokinase may interact with tobacco contents or betel quid constituents to break down oral epithelium and thus enhance tumor formation, which might explain the high proportion of oral cancer patients who both smoke and chew betel quid. Our study provided genetic evidence for this hypothesis.

In conclusion, our study provides evidence that the urokinase gene is associated with oral cancer. The " $T$ " allele of the $3^{\prime}$-UTR region in the urokinase gene is highly correlated with cancer patients.

\section{REFERENCES}

1. Clayman G, Wang SW, Nicolson GL, et al. Regulation of urokinase-type plasminogen activator expression in squamous-cell carcinoma of the oral cavity. Int J Cancer 1993;54:73-80.

2. Ljungner $\mathrm{H}$, Bjorlin $\mathrm{G}$, Astedt B. Immunological identification of plasminogen activators in normal and malignant tissues of the oral cavity in man. Int J Oral Surg 1984;13:334-338.

3. Nozaki S, Endo Y, Kawashiri S, et al. Immunohistochemical localization of a urokinase-type plasminogen activator system in squamous cell carcinoma of the oral cavity: association with mode of invasion and lymph node metastasis. Oral Oncol 1998;34:58-62.

4. Ko YC, HuangYL, Lee CH, Chen MJ, Lin LM, Tsai CC. Betel quid chewing, cigarette smoking, and alcohol consumption related to oral cancer in Taiwan. J Oral Pathol Med 1995;24:450-453.

5. Jayant K, Balakrishnan V, Sanghvi LD, Jussawala DJ. Quantification of the role of smoking and chewing habits in oral, pharynx, and esophageal cancer. Br J Cancer 1977;35: 232-235.

6. Jeng JH, Kuo ML, Hahn LJ, Kuo MYP. Genotoxic and nongenotoxic effects of betel quid ingredients on oral mucosal fibroblasts in vitro. J Dent Res 1994;73:1043-1049.

7. Das BR, Nagpal JK. Understanding the biology of oral cancer. Med Sci Monit 2002;8:RA258-RA267.

8. Tripputi P, Blasi F, Verde P, Cannizzaro LA, Emanuel BS, Croce CM. Human urokinase gene is located on the long arm of chromosome 10. Proc Nat Acad Sci USA 1985;82:4448-4452.

9. Conne B, Berczy M, Belin D. Detection of polymorphism in the human urokinase-type plasminogen activator gene. Thromb Hemost 1997;77:434-435.

10. Yasuda T, Sakata Y, Kitamura K, Morita M, Ishida T. Localization of plasminogen activators and their inhibitor in squamous cell carcinomas of the head and neck. Head Neck 1997;19:611-616.

11. Barlow Y, Southam JC. Plasminogen activators in normal and malignant oral epithelium in vivo and in vitro. Arch Oral Biol 1992;37:749-756.

12. Epstein JB, Zhang L, Rosin M. Advances in the diagnosis of oral premalignant and malignant lesions. $\mathrm{J}$ Can Dent Assoc 2002;68:617-621.

13. Sundqvist K, Liu Y, Nair J, Bartsch H, Arvidson K, Grafstrom RC. Cytotoxic and genotoxic effects of areca nut-related compounds in cultured human buccal epithelial cells. Cancer Res 1989;49:5294-5298.

14. Chang YC, Hu CC, Tseng TH, Tai KW, Lii CK, Chou MY, Synergistic effects of nicotine on arecholine-induced cytoxicity in human bucosal fibroblasts. J Oral Pathol Med 2001;30:458-464. 